\title{
As múltiplas leituras da 'metáfora': desenhando uma metodologia de investigação
}

\author{
Multiplereadingsof 'metaphor': \\ designing a methodology of investigation
}

Mara Sophia Zanotto

Pontifícia Universidade Católica de São Paulo-PUC-SP - São Paulo - São Paulo - Brasil

\begin{abstract}
Resumo:O objetivo deste artigo é apresentar e discutir epistemologicamente o desenho de uma metodologia de investigação sobre osprocessos de interpretação de metáforas em textos literários na interface com osprodutos, ou seja, suas múltiplas leituras. A motivação da pesquisa desde o início foi investigar o que a 'metáfora' realmente significa para o 'leitor empírico', contribuindo, assim, para elucidar os processos sociocognitivos que podem ocorrer durante sua interpretação. A metodologia adotada é a qualitativa, de orientação interpretativista. $O$ método principal, cujo processo de construção é o foco central do trabalho, é o Pensar Alto em Grupo, que resultou de uma adaptação do Protocolo Verbal. Esse método é associado a diários e entrevistas, para possibilitar a triangulação dos dados. Para verificar se há variação dos processos e das leituras da 'metáfora', tornou-se necessário gerar dados com vários grupos de leitores, constituindo assim um estudo de caso coletivo como estratégia de pesquisa. Esse desenho metodológico se insere no paradigma interpretativista, cuja epistemologia é a do dialogismo.
\end{abstract}

Palavras-chave:Metáfora. Metodologia. Interpretativismo, Dialogismo. Pensar Alto emGrupo.

Abstract: This article aims to introduce and discuss epistemologically the design of a research methodology on the processes for interpreting metaphors in literay texts in the interface with the product, i.e., their multiple readings. The research motivation, from the beginning, was investigating what 'metaphor' really means to the 'empirical reader', thus contributing to elucidate the social and cognitive processes that may occur during its interpretation. The methodology adopted is qualitative, with an interpretive orientation. The main method, whose construction process is the major focus of this paper, is Group-Think Aloud, which is derived from an adaptation of the Verbal Protocol. This method is associated with diaries and interviews, to enable the triangulation of data. To investigate whether there is variation in the processes and readings of 'metaphor', it became necessary to generate data with various groups of readers, thus constituting a collective case study as research strategy. This methodological design falls within the interpretive paradigm, whose epistemology is that of dialogism.

Keywords: Metaphor. Methodology.Interpretive research.Dialogism. GroupThinkAloud. 


\section{Introdução}

O objetivo deste artigo é apresentar e discutir epistemologicamente o desenho de uma metodologia de investigação sobre osprocessos de interpretação de metáforas em textos literários na sua interface com osprodutos, ou seja, asmúltiplas leituras. A motivação da pesquisa desde seu início foi investigar o que a 'metáfora' realmente significa para o 'leitor empírico' (BAKHTIN, 2003), contribuindo, assim, para elucidar os processos sociocognitivos que podem ocorrer na sua interpretação. Trabalhando com leitores reais, dando condições para que eles construam livremente os sentidos, é esperado que emerjam múltiplas leituras, as quais exigirão um estudo de sua natureza semântico-pragmática. Nesse sentido, a interface entre processos e produtos possibilitará a discussão da relevância das leituras (CARSTON, 2002), com base na coerência da sua construção pelos leitores. Atingindo esses objetivos, a pesquisa poderá contribuir para explicar dimensões da significação da 'metáfora' em uso.

Por que esse tema é importante? Como esta pesquisa se insere na Linguística Aplicada interdisciplinar/transdisciplinar

(SIGNORINI; CAVALCANTI, 1998), que tem como traço essencial ouvir as vozes dos participantes das práticas sociais investigadas (MOITA LOPES, 2006) e construir conhecimento útil para eles, a pesquisa também tem o objetivo de contribuir para a solução de um problema socialmente relevante, que é o ensinoaprendizagem de leitura. Essa é uma concepção da Linguística Aplicada (LA) de inspiração pós-moderna, que se opõe à "pesquisa modernista que apagou o sujeito social na produção de um conhecimento positivista, quantificável, experimental, generalizável e objetivista" (MOITA LOPES, 2013, p.16). Assim a LA recupera o sujeito e "o coloca como crucial em sua subjetividade ou intersubjetividade, tornando-o inseparável do conhecimento produzido sobre ele mesmo, assim como das visões, valores e ideologias do próprio pesquisador." (MOITA LOPES, 2013, p.17).
Essa concepção da LA não se reduz a uma aplicação de teorias, pois ela se caracteriza pela inter/transdiciplinaridade, num movimento em que as teorias são buscadas pela sua pertinência para explicar dimensões do fenômeno investigado, podendo ter como consequência uma contribuição para explicar lacunas das teorias, ou para uma elaboração teórica mais complexa. Por me identificar com esse modo de produção do conhecimento, a pesquisa que venho desenvolvendo está afinada com a epistemologia que sustenta essa concepção da Linguística Aplicada e que será discutida neste trabalho. Desse modo, a pesquisa desenvolvida em diferentes projetos tem um foco aplicado e um foco nas teorias.

Do ponto de vista aplicado, pode-se perguntar por que pesquisar a compreensão da metáfora é relevante, se no Brasil os problemas de alfabetização e de leitura são sérios e graves, como evidenciam as avaliações institucionais, como ENEM, SAEB e PISA, cujos resultados e possíveis causas são objeto de relevantes reflexões de Rojo (2009) e de outros estudiosos da área de letramento no Brasil. Diante de tão graves problemas, pode-se perguntar se não seria um tanto supérfluo preocupar-se com a compreensão da metáfora.

$\mathrm{E}$ à primeira vista, parece ser mesmo. No entanto, a 'metáfora' parece constituir um dos principais problemas na leitura do texto literário, devido às incongruências ${ }^{1}$ (CAMERON, 2003) que ela apresenta, as quais afastam os leitores, por desconhecerem o seu papel no processo de interpretação da 'metáfora'. Nos dois estudos de caso realizados (ZANOTTO; PALMA, 2008; ZANOTTO, 2010), o processo de construção de sentidos desencadeado pelas incongruências se mostrou muito produtivo, por envolver um complexo processamento em cadeia de inferências metonímicas e metafóricas, que nos levaram a questionar a própria natureza da metáfora. O que pensávamos ser 'uma metáfora' se revelou um

\footnotetext{
${ }^{1}$ As incongruências podem ser semânticas, quando apresentam incompatibilidades linguísticas em partes do enunciado ou de uma expressão; e pragmáticas, quando provocam um ruptura da relevância em relação ao contexto (ZANOTTO, 2010, P. 617).
} 
fenômeno complexo e híbrido, pois sua interpretação envolveu processamentos metonímicos e metafóricos nos dois estudos de caso, por isso não é mais possível falar simplesmente em metáfora. Esses resultados têm implicações teóricas e aplicadas.

Do ponto de vista teórico, surgem inúmeras questões: que fenômeno é esse que estou/estamos investigando? Teria razão Goossens (2003) de propor o termo metaftonímia? Essa interação de processamentos metafóricos e metonímicos ocorre sempre no processo de interpretação? Haverá diferentes tipos de interação desses processamentos?Eles constituem padrões que se repetem ou são muito variáveis? Para poder responder a essas questões, realizarei mais pesquisas empíricas com o desenho metodológico que será apresentado e discutido neste trabalho.

Ainda do ponto de vista aplicado, os resultados são relevantes para sugerir mudanças no ensinoaprendizagem de leitura, pois entre as capacidades exigidas no ENEM, estão as habilidades inferenciais contextualizadas, que, no entanto, não são trabalhadas na prática escolar de leitura, já que a atividade de ler na escola consiste em repetir literalmente o que 'o texto diz'. Desse modo, o ENEM passa a ser uma avaliação perversa, pois avalia o aluno em relação a uma habilidade que ele não desenvolveu na escola; e o professor, por sua vez, também não recebeu uma formação que the possibilite trabalhar em sala de aula com a leitura inferencial. $E$ as pesquisas desenvolvidas por mim e participantes do projeto mostram que trabalhar com interpretação de metáfora e metonímia pode contribuir muito para desenvolver o raciocínio inferencial do leitor.

Do ponto de vista teórico, há uma lacuna nos estudos de letramento, apontada pelo próprio Street (2003), ao dizer que houve um número muito amplo de estudos etnográficos, que tiveram o objetivo de observar práticas de letramentos em inúmeros contextos em diferentes países, mas falta ainda explicar como os sentidos são construídos. A mesma lacuna é apontada nos estudos mais recentes sobre a relevância, propostos por Carston (2002), porque ainda não se conseguiu explicar o que ocorre no espaço que há entre o sentido lexical e os conceitos ad hoc, especificamente no caso da metáfora. Os conceitos ad hoc, segundo Carston (2002, p.322), "não são linguisticamente dados, mas são construídos online em resposta a expectativas específicas de relevância surgidas em contextos específicos". Embora os conceitos adhoc possam explicar interessantes aspectos dos sentidos metafóricos, algo relevante permanece sem explicação, ou seja, "a questão crucial de como construímos os conceitos ad hoc" (TENDHAL, 2009, p.86). Assim, pesquisar empiricamente a compreensão da metáfora e da metonímia com leitores reais pode contribuir para elucidar essa lacuna.

Para realizar a pesquisa foi necessário desenhar uma metodologia de investigação que possibilitasse responder às questões de pesquisa relativas aos processos e aos produtos da interpretação da metáfora. Para apresentar a construção do desenho metodológico, o texto está estruturado em cinco partes, iniciando pela explicitação da noção de paradigma e de desenho da investigação.

\section{Paradigma e desenho de investigação}

Antes de passar para a questão do método, é necessário explicitar como se define, neste trabalho, um desenho de investigação, ou planejamento de pesquisa. A definição adotada é a de Denzin e Lincoln (2006, p. 36), segundo a qual, um desenho de investigação"descreve um conjunto flexível de diretrizes que vinculam os paradigmas teóricos primeiro às estratégias de investigação $\mathrm{e}$, em segundo lugar, aos métodos para a coleta de materiais empíricos." (grifos meus)

Essa concepção de planejamento faz surgir uma discussão sobre paradigma, que tem sido um conceito problematizado por alguns autores, como, por exemplo, Creswell (2010), que prefere falar em concepções filosóficas. No entanto, Guba e Lincoln (1998) propõem uma definição consistente e coerente 
de paradigma como um sistema de crenças básicas baseadas em assunções epistemológicas, ontológicas e metodológicas. Isso significa dizer que todo paradigma revela uma forma de ver a realidade (ontologia), ou o objeto no mundo, assim como uma concepção de conhecimento dessa realidade (epistemologia) e o modo pelo qual podemos conhecer o que pode ser conhecido dessa realidade (metodologia).

Denzin e Lincoln (1998) afirmam também que é importante que o pesquisador explicite o paradigma que informa e guia sua pesquisa. Essa observação é similar à de Moita Lopes (1994), quando apontava, na década de 90, a necessidade de a Linguística Aplicada construir um metaconhecimento sobre a produção de conhecimento na área, por ser"extremamente importante para o seu desenvolvimento" (MOITA LOPES, 1994, p.330). Da mesma maneira, considero que é necessário que o pesquisador também construa um metaconhecimento sobre o seu processo de investigação. Por me identificar com o pensamento desses autores, essa tem sido a minha preocupação no desenvolvimento da pesquisa. Por essa razão, propus como objetivo deste trabalho apresentar e discutir epistemologicamente o desenho de investigação.

$\mathrm{Na}$ elaboração do desenho de pesquisa, o problema mais relevante que ocorreu foi em relação ao método, que exigiu um processo de busca para se adequar ao que eu pretendia conhecer: o processo de compreensão da metáfora por leitores reais e o produto das múltiplas leituras. Porissocomeço a relatar a busca do método.

\section{Como pesquisar a compreensão da metáfora? A busca de um método}

O início da minha pesquisa sobre a elucidação do processo de compreensão da metáfora se deu no paradigma cognitivista, que propunha a metodologia introspectiva. Essa metodologia surgiu na psicologia cognitiva e foi adotada pela Linguística Aplicada nas pesquisas sobre leitura, nas décadas de 1980 e 1990. Os pesquisadores da área utilizavam os seguintes métodos: o protocolo verbal, ou pensar alto, os diários e a retrospecção (NUNAN, 1992).

Dentre esses métodos, o protocolo verbal parecia ser o mais adequado para investigar o processo de compreensão da metáfora, por possibilitar o acesso aos processos mentais que ocorriam durante a compreensão da metáfora, Por essa razão ele foi eleito 0 método principal do desenho metodológico.

Passo a expor o seu histórico, começando pela sua utilização no quadro teórico de processamento de informação e na teoria de Solução de Problemas até seu percurso nas áreas aplicadas, para em seguida apresentar sua utilização na minha pesquisa.

\subsection{Protocolo Verbal - Origem}

Protocolo verbal é a gravação dos processos de pensamento verbalizados (ou elicitados) por uma pessoa pensando alto durante a realização de uma tarefa ou resolução de um problema. Os dados produzidos por essa técnica podem contribuir para investigar os processos cognitivos subjacentes.

Sua origem remonta ao séc. XIX, quando foi introduzido por William James (1890), na pesquisa qualitativa em psicologia, com a publicaçãodo livro The principlesofpsychology, no qual o autor relatava o que as pessoas diziam sobre o próprio pensamento (PRESSLEY; HILDEN, 2004, p. 308). No entanto, com o advento do behaviorismo, o protocolo verbal caiu em descrédito, não sendo reconhecido pela ciência positivista como técnica válida de pesquisa, pois, para os behavioristas, a mente não podia ser objeto de conhecimento.

Após esse período de descrédito, os protocolos verbais ressurgiram nos anos 1970 "como a maior fonte de dados para a pesquisa cognitiva" (ERICSSON\& SIMON, 1987, p. 24). De acordo com Ericsson e Simon (1987, p. 25), seu ressurgimento foi marcado pelas obras de Newell, Shaw e Simon (1958) e Newell e Simon (1972), nas quais o protocolo verbal foi utilizado como técnica de pesquisa para verificar os processos cognitivos que ocorriam durante a solução de problemas, no 
quadroteórico de processamento de informação. A partir dessas pesquisas, o protocolo verbal passou a desempenhar um papel inquestionável na Teoria de Solução de Problemas, nas teorias de processamento de informação, que se desenvolveram com o aparecimento do computador na década de 1950.

Devido às críticas dos behavioristas ao protocolo verbal como técnica de pesquisa, Ericsson e Simon (1984) consideraram que era muito importante construir uma base teórica sólida para o uso do protocolo verbal como fonte científica de dados. Com esse objetivo, eles elaboraram o livro: ProtocolAnalysis: Verbal Report as Data, que, segundo MacKay (2009), é considerado uma obra seminal sobre a análise do protocolo, pois consolidou teoricamente o uso do protocolo verbal como uma técnica para obter dados, que possibilitariam a inferência dos processos cognitivos dos sujeitos a partir da interpretação do pesquisador (ERICSSON; SIMON, 1987, p.25).

\subsection{Conflito de epistemologias}

A década de 1980 passou a ser considerada o marco inicial do paradigma cognitivista, para o qual a cognição se tornou o objeto de investigação, ao invés do comportamento. Assim, ao propor os métodos introspectivos, como o protocolo verbal e a retrospecção, sob a forma de entrevistas e questionários, o cognitivismo pretendia acessar o que se passava na mente dos informantes ao realizar uma tarefa, o que era visto como algo impossível pelos behavioristas. Desse modo, houve um período de calorosas críticas dos behavioristas aos psicólogos e psicolinguistas cognitivistas.

Esse conflito dos dois paradigmas ocorreu, porque o cognitivismo tinha pressupostos opostos aos do behaviorismo, pois os cognitivistas tinham uma visão da mente como um objeto que podia ser conhecido e, de forma coerente com essa ontologia, propunham métodos introspectivos para acessar o que se passava na mente do ser humano (metodologia). Consequentemente, do ponto de vista epistemológico, o próprio sujeito poderia falar o que estava pensando durante a realização de uma tarefa ou resolução de um problema, produzindo dados que seriam interpretados pelo pesquisador.

O behaviorismo, por sua vez, não considerava necessária a noção de mente. Pode-se dizer que, para eles, a mente era uma caixa preta, pois não era possível acessar os processos mentais do ser humano quando submetido a um estímulo. Só era possível ter o produto ou resultado desse estímulo, ao passo que os cognitivistas se interessavam pelo processo. No caso das pesquisas em leitura, o texto seria o estímulo, e o produto seria o resultado da compreensão escrita ou oral do texto. Assim o texto era, do ponto de vista ontológico, um objeto separado do sujeito, com propriedades imanentes, que deviam ser percebidas por todos os leitores da mesma maneira. Se os sentidos já estavam no texto, eles deviam ser objetivamente captados pelos leitores, que tinham suas subjetividades desprezadas.

Como esses paradigmas tinham visões opostas, houve um período de conflito acirrado, que com o tempo se amainou, mas não terminou, porque ainda há pesquisadores, de ambos os lados, que não aceitam a visão oposta. Por outro lado, como observam Denzin e Lincoln (1998, p.9) há pesquisadores que são mais abertos a outras formas de pensar e que "argumentam que os métodos positivistas são apenas um modo de contar a história sobre a sociedade ou o mundo social. Eles podem não ser melhores ou piores que qualquer outro método: eles simplesmente contam um tipo diferente de história".

No caso das pesquisas empíricas sobre a compreensão da metáfora, pode-se concluir,a partir da importante observação de Gibbs (1999), que há necessidade de diferentes métodos que possam capturar diferentes dimensões do processo de compreensão. Gibbs (1999, p.38) observa que os estudiosos falam em processo de compreensão da metáfora como se fosse um fenômeno único e homogêneo, "em vez de um processo que ocorre num tempo real ao longo de uma variedade de dimensões temporais, que se inicia nos primeiros milissegundos 
de processamento inconsciente e estende-se até o longo prazo, a análise reflexiva".

Assim, admitindo-se que o processo de compreensão da metáfora é complexo e multifacetado, é necessário que o pesquisador recorra a diferentes metodologias para obter dados das suas diferentes dimensões, por exemplo, os experimentos podem ser mais adequados para capturar os processos inconscientes, enquanto os métodos introspectivos, para acessar os processos conscientes. Desse modo, cada método pode contar melhor uma história.

No caso da minha pesquisa sobre a compreensão da metáfora, o protocolo verbal (e sua adaptação que gerou o Pensar Alto em Grupo) pode produzir dados da leitura mais reflexiva e consciente, enquanto os experimentos podem ser mais adequados para capturar os processos inconscientes. Assim cada método vai "fotografar" um aspecto ou dimensão do processo de compreensão da metáfora.

Além disso, a escolha do método é influenciada também pelo tipo de texto e pelo tipo de metáfora. A escolha pelo texto poético se justifica pelo fato de esse tipo de texto apresentar metáforas difíceis, verdadeiros enigmas, que provocam um 'conflito intelectual desestabilizador' (SCHNEUWLY; DOLZ, 2004, p.103), o qual leva à desautomatização do processo de leitura, tornando-o mais consciente e estimulando, naturalmente, o pensar alto para resolver o enigma. No entanto, para que o conflito desestabilizador fosse produtivo e não paralisante, houve a necessidade de adaptação do método.

Antes de iniciar o relato da construção do método, vou apresentar sua utilização nas áreas aplicadas, mais especificamente em pesquisas sobre leitura e sobre a compreensão da metáfora.

\subsection{Protocolo verbal nas áreas aplicadas e suas adaptações}

Como vimos, no início, o protocolo verbal foi um dos principais métodos para estudar os processos cognitivos na Psicologia Cognitiva, na Ciência Cognitiva e na Análise do Comportamento. Mas logo
- método ultrapassou as fronteiras das ciências cognitivas para se expandir nas áreas aplicadas, como a educação, a linguística aplicada. Nessas áreas, passou a ser utilizado nas pesquisas em leitura (HOSENFELD, 1976,1977; OLCHAVSKY, 1976; CAVALCANTI, 1983, 1987; PRESSLEY; AFFLERBACH, 1995), na aprendizagem de língua estrangeira (FAERCH; KASPER, 1987) e na compreensão da metáfora (ZANOTTO, 1988,1992; STEEN, 1992, 1994; CAMERON, 2002,2003).

Na linguística aplicada brasileira, pode-se dizer que ele foi introduzido por Cavalcanti $(1983,1989)$ na pesquisa em leitura, que constituiu o foco de atenção dos pesquisadores da área no período do cognitivismo (COHEN, 1987).

Nessa expansão para outras áreas, o protocolo verbal passou por várias transformações ou adaptações. Como relata Cavalcanti (1989),esse método foi utilizado em pesquisas sobre leitura em língua estrangeira por Hosenfeld $(1976,1977)$ e, em língua materna, por Olchavsky (1976); e ambas sentiram necessidade de fazer adaptações. Hosenfeld, por exemplo, realizou o protocolo verbal associado com técnicas de entrevista. Já Olchavsky solicitava aos leitores que pensassem alto após a leitura de cada oração de um conto, o que tornava a leitura um processo artificial.

Para realizar a adaptação em sua pesquisa, Cavalcanti desenvolveu quatro estudos pilotos para tomar decisões em relação ao tipo de texto usado, às instruções a serem dadas ao sujeito e ao papel do pesquisador na coleta de dados (CAVALCANTI, 1989, p.148). O resultado desses estudos foram os protocolos de pausa, que "consistem em solicitar aos sujeitos para ler silenciosamente, com o propósito de fazer um resumo oral e pensar alto toda vez que notarem a ocorrência de pausa no processo de leitura" (CAVALCANTI, 1989, p. 153).

Nos estudos sobre a compreensão da metáfora em linguística aplicada, o protocolo verbal foi utilizado por Cameron (2002, 2003), que se baseou no trabalho de Steen (1992). A adaptação de Cameron $(2002,2003)$ teve como resultado o que ela denominou 'Goal-DirectedInteractiveThink-Aloud' 
(Pensar Alto Interativo Dirigido a um Objetivo), cuja sigla é GITA. Ela definiu o GITA como falar-e-pensar colaborativamente em grupo e enfatizou que esse método "possibilita que as vozes dos estudantes tenham um lugar na pesquisa sobre a compreensão da metáfora, mas sem solicitar diretamente a eles uma explicação da metáfora linguística" (CAMERON, 2003, p. 153).

Steen $(1992,1994)$ utilizou o protocolo verbal na pesquisa da compreensão da metáfora, na área de estudo empírico da literatura. Ele usou o pensar alto simultâneo frase-por-frase, na compreensão da metáfora no texto literário, realizando, portanto, uma adaptação semelhante à de Olchavsky. Além disso associou-o a métodos experimentais.(Há um artigo recente de Steen (2013) sobre uma pesquisa de compreensão da metáfora visual com o pensar alto)

Ainda nos estudos da metáfora em linguística aplicada, o protocolo verbal foi usado por mim(ZANOTTO, 1988, 1992) e por pesquisadores do projeto (NARDI, 1993; CANOLLA, 1995), primeiramente, na sua forma original, ou seja, realizado individualmente com 0 suporte da pesquisadora, que não podia interferir a não ser para lembrar o informante que pensasse alto, caso ele ficasse em silêncio.No entanto, a forma convencional não produziu os resultados desejados e houve um processo de busca por uma adaptação, como vou relatar a seguir.

\subsection{A construção / adaptação do método}

Nesta parte vou relatar as etapas da adaptação do protocolo verbal para atender aos objetivos da pesquisa sobre a compreensão da metáfora e suas múltiplas leituras. Esse relato será detalhado, pois tem o objetivo também de esclarecer pesquisadores interessados na utilização desse método.

Concordo com Pressley e Hilden (2004, p. 31) quando dizem que pesquisadores da educação consideram que a metodologia do protocolo verbal não pode ser padronizada, pois "os estudos do protocolo verbal podem ser adaptados de forma flexível às questões feitas pelo pesquisador, ao invés de as questões terem que ser ajustadas à metodologia de pesquisa". Entretanto, os autores concordam com a observação de Afflerbach (2000)de que essa flexibilidade na utilização do método faz surgir a necessidade de que os pesquisadores devam fornecer informação detalhada sobre como desenvolveram seus estudos.

No caso da minha pesquisa, essa exigência se tornou mais relevante, porque a adaptação levou a uma transformação que implicou em mudança epistemológica, pois o protocolo verbal consistia, na sua origem, numa tarefa individual e monológica, e o que resultou foi uma prática dialógica e colaborativa de Pensar Alto em Grupo (ZANOTTO,1995,1998), que é uma prática afinada com os pressupostos do interpretativismo e do dialogismo, que serão discutidos mais adiante neste trabalho, pois antes vou relatar o processo de construção do método, que passou pelas etapas de um estudo piloto e uma metapesquisa.sobre o próprio método.

\section{- O estudo piloto}

No início da minha pesquisa, resolvi realizar um estudo piloto com duas alunas, que se sentiam motivadas para viver a experiência de pensar alto enquanto liam uma poesia do Drummond de Andrade. A motivação delas vinha do fato de terem o objetivo de utilizar o método nas suas pesquisas, enquanto o meu objetivo era "investigar a técnica adequada para elicitação de dados" (ZANOTTO, 1988, p. 176) para responder às questões da pesquisa.

Nesse estudo piloto, já usei uma adaptação do protocolo verbal proposta por Cavalcanti (1983): o protocolo de pausa, porque, como no texto havia metáforas difíceis que provocariam uma desautomatização do processo de leitura, era esperado que as leitoras fizessem pausas espontaneamente.

Elas realizaram o pensar alto individualmente e, imediatamente após, fizeram uma entrevista retrospectiva, na qual relataram que ficaram bem à vontade durante a experiência. Mas, como o texto tinha metáforas difíceis, que constrangeram um pouco a atividade de pensar alto devido às 
incongruências, propus outra entrevista retrospectiva três dias após, pois era possível que, nesse intervalo, ocorressem outras interpretações espontaneamente. Era importante saber se a experiência tinha sido bem sucedida, pois isso indicaria que o método estava adequado. No entanto, nessa entrevista, ambas confessaram que, na verdade, não tinham se sentido bem durante o pensar alto, porque ficaram o tempo todo preocupadas em saber se o que estavam fazendo era o que eu esperava delas, pois não conseguiam apagar a ideia de que eu era professora. Por essa razão sugeriram que a experiência fosse realizada com um colega, pois, assim, elas se sentiriam mais à vontade.

Esse fato me levou a acrescentar uma outra etapa na busca de um método adequado para elicitação de dados: a discussão espontânea do texto em sala de aula. No fundo eu já estava testando a atividade em grupo nas aulas de estilística, nas quais eu trabalhava com as figuras em textos literários e de outros gêneros e achava que, antes de analisar estilisticamente um texto, era importante compreendê-lo. Percebi que a atividade em grupo deu bons resultados porque "como nenhum aluno se sentiu foco de atenção, as associações ocorreram livremente, na tentativa de resolver o enigma constituído pela metáfora, além do que a associação de um aluno estimulava a do outro"(ZANOTTO, 1988, p.180).

Assim já havia indícios de que em grupo poderia ser mais produtivo. Mas ainda levaria um tempo para chegar lá, pois, levando em conta a sugestão das alunas de ter um ou uma colega como suporte técnico ao invés da professora, Cavalcanti e eu resolvemos realizar a metapesquisa sobre 0 protocolo verbal, que será relatada a seguir.

\section{- Metapesquisa sobre o protocolo verbal}

A meta-pesquisa sobre o protocolo verbal foi realizada num curso ministrado por Marilda Cavalcanti e por mim, intitulado:Pesquisa sobre Leitura e Escrita em Língua Materna. Os alunos eram pós-graduandos de várias universidades brasileiras e participavam do curso de férias promovido pelo Programa de Pós-Graduação em Linguística Aplicada e Estudos da Linguagem, da PUC-SP. O foco do curso era o protocolo verbal como método para pesquisa em leitura ou escrita. Para que os pósgraduandos conhecessem melhor o protocolo verbal e, ao mesmo tempo, produzissem dados para nossa meta-pesquisa, elaboramos um desenho metodológico levando em conta a sugestão das alunas que haviam participado do estudo piloto. Assim os alunos vivenciariam duas das três situações propostas: a) a realização do pensar alto com o suporte de um colega;b) com o suporte de uma das pesquisadoras; c)sem suporte de uma pessoa, ou seja, sozinho com o gravador. Propusemos também dois tipos de textos: poesias, de Drummond de Andrade, ou Fábulas, do Millor Fernandes (CAVALCANTI; ZANOTTO, 1994).

O desenho da pesquisa tinha duas fases: na primeira, os alunos deviam escolher o poema ou a fábula e também o tipo de sessão, ou seja, com o suporte do colega, ou de uma das professoras/pesquisadoras, ou sem suporte de uma pessoa. Entre os doze mestrandos e doutorandos, apenas quatro escolheram o poema, e os oito restantes, a fábula. Esse fato já demonstrou uma resistência para ler o poema. $\mathrm{Na}$ segunda fase, deviam inverter: quem havia lido o poema, deveria ler a fábula. Quem havia tido o suporte de um colega, deveria realizar o pensar alto com uma das professoras ou sozinho com o gravador. No entanto, como na primeira fase, os informantes tinham demostrado resistência em relação à leitura do poema e, também, em relação à realização do pensar alto sozinho, decidimos que a segunda fase seria realizada apenas com voluntários. O resultado foi que apenas dois escolheram o poema e dois, a fábula.De acordo com o desenho planejado, deveríamos ter seis alunos lendo o poema na primeira fase e outros seis na segunda fase, mas o resultado final foi que quatro escolheram o poema na primeira fase e dois, na segunda, totalizando seis. Esse resultado já apontava que havia problema com a poesia.

Ao analisar os dados de interpretação do poema Destruição, de Drummond de Andrade, mostro, em Zanotto (1992), depoimentos dos leitores 
que evidenciam como as incongruências de certas metáforas constituíram problema para eles, que reagiam negativamente a elas. Essa reação evidencia que as alunas desconheciam 0 papel das incongruências, pois elas são a condição necessária da metáfora, pelo fato de funcionarem como um gatilho para a interpretação metafórica.

Nos dados da meta-pesquisa, três informantes pararam no estágio da percepção da incongruência e três construíram diretamente uma hipótese de interpretação dos versos da terceira estrofe do poema: "Nada, ninguém. Amor, puro fantasma/ que os passeia de leve, assim a cobra/se imprime na lembrança de seu trilho".(Destruição, In ANDRADE, C.D. Lição de Coisas, p.337). Apresento as interpretações de duas informantes:

Informante 3 - Assim a cobra se imprime na lembrança de seu trilho. Cobra aí no sentido de passa o réptil e fica só alguma coisa e assim é o amor, que passa em cima e passa pelo indivíduo e fica um leve traço? Em que ele não é reto, ele é cheio de curvas, mas é lembrança?(ZANOTTO, 1992, p. 243)

Informante 6 - puro fantasma que os passeia de leve assim a cobra se imprime na lembrança do seu trilho. São as marcas do amor... (ZANOTTO, 1992, p. 243)

O informante 3 termina com uma pergunta pedindo confirmação, mas a pessoa que estava como suporte não podia responder, e o informante 6 não especifica que marcas do amor seriam, e não se podia perguntar por que havia interpretado assim. E nossos trabalhos mais recentes têm mostrado que as perguntas podem ser importantes desde que não sejam diretivas, pois, ao perguntar ao leitor porque interpretou desse modo, muitas vezes o leitor elicita (retrospectivamente)o raciocínio que realizou na construção da leitura.

Logo em seguida, testei novamente a discussão espontânea em grupo e obtive dados mais relevantes para a pesquisa, como mostra a fala da informante M:

Ele tá falando da cobra o tempo todo, mas uma coisa que me chamou a atenção nessa estrofe é que...que eu acho que a comparação também se dá, é na questão de fantasma. Ela num tá lá, ela imprime a lembrança dela, né? No trilho que ela mesma deixou, e o amor também não está, ele só imprimiu uma lembrança dele, entendeu, então? Amante não existe porque é destruído, o amor que deveria então ficar também não fica porque é puro fantasma. Então... não resta nada. (ZANOTTO, 1992, p. 243)

A fala dessa aluna evidencia o raciocínio detalhado em que ela faz o mapeamento entre a cobra e o amor na interpretação dos versos da terceira estrofe.

Houve outro fator negativo na experiência que se evidenciou nos relatórios de vivência, que foram solicitados após as sessões do pensar alto nas duas fases.Nos relatórios, eles confessaram que, em qualquer uma das situações, ficaram preocupados em relação ao que esperávamos deles, ou seja, mesmo que não estivéssemos presentes,não se cancelava a interação com as pesquisadoras.

O fato de terem essa preocupação se devia, em grande parte, ao fato de a professora/pesquisadora ficar ao lado só observando e não interagindo normalmente, o que criava uma situação desconfortável e o pensar alto não fluía. Dessa forma, o resultado foi que uma metade dos informantes interpretou superficialmente, sem produzir evidências do processo, e a outra metade não conseguiu interpretar as metáforas e terminaram a experiência se desqualificando como leitores de texto literário (ZANOTTO, 1992, 2014). E eu não obtive dados relevantes das múltiplas leituras da metáfora. Desse modo, resolvi abandonar o pensar alto individual, pois concluí que não era adequado para minha pesquisa.

\subsection{A construção do Pensar Alto em Grupo (PAG)}

A realização do estudo piloto e da metapesquisa sobre o protocolo verbal, cujos dados foram sendo triangulados com os da discussão espontânea de texto, levaram à conclusão de que a leitura em grupo era mais adequada para obter dados relevantes para a pesquisa. Mesmo assim, para obter mais uma comprovação, resolvi propor para um grupo de pós-graduandos a leitura em grupo de uma poesia 
de Drummond de Andrade. Procurei criar uma situação em grupo, na qual os leitores se sentissem bem à vontade para ler de forma livre e descompromissada. Para isso dei espaço para a voz e subjetividade dos leitores, buscando interferir o mínimo possível, apenas incentivando-os a falar o que estavam pensando e estimulando o grupo a ouvilos, assim como eu devia demonstrar que estava ouvindo. A prática de leitura em grupo se deu no contexto de uma disciplina de pós-graduação, no final do semestre, quando todos já se conheciam bem e estavam familiarizados com a professora e os colegas, ou seja, não foi um grupo montado especificamente para uma coleta de dados. Esse aspecto é importante, porque cria um contexto favorável para a atividade ser espontânea e produtiva.

A atividade se deu na prática da seguinte maneira: o texto foi distribuído aos participantes e orientei que fizessem, primeiramente, uma leitura silenciosa e introspectiva. Se quisessem, podiam registrar as ideias que viessem à mente, para depois discutir em grupo. Caso sentissem alguma dificuldade, não precisariam se preocupar, pois poderíamos pensar juntos para resolvê-la. Após a leitura silenciosa, a conversa se iniciou e cada um pode falar livremente a respeito do texto e do seu processo de leitura. Não propus nenhuma tarefa ou qualquer direção prévia à atividade, pelo contrário, as ideias devem fluir livremente e não constituir objeto de avaliação. Como coordenadora, abri mão do papel de autoridade interpretativa e de controlador dos turnos e apenas coordenei a discussão (ZANOTTO, 1998, p. 21).

A vivência foi muito bem sucedida, tanto do ponto de vista da pesquisa, como - para minha surpresa - do ensino,mas, apenas muitos anos mais tarde e muitas pesquisas depois, é que focalizei, no texto de 2014, o PAG como prática de letramento para o ensino-aprendizagem de leitura, por razões que serão explicadas mais adiante. Para a pesquisa, os dados revelaram momentos de retrospecção imediata de leituras construídas introspectivamente e momentos de construção online de leituras, nos quais
- grupo co-construiu um raciocínio coletivo (PONTECORVO, 1995). Essas características me autorizaram a denominar o método de Pensar Alto em Grupo.

Além dessa confirmação, as pesquisas de Palma (1998) e Nardi (1999) contribuíram para confirmar o potencial do método, pois os participantes de suas pesquisas passaram pela experiência das duas modalidades: o pensar alto individual e o pensar alto em grupo, levando à conclusão de que o PAG produzia dados mais ricos.

Essa adaptação do protocolo verbal para Pensar Alto em Grupo provocou uma mudança de paradigma: estávamos saindo do cognitivismo que focalizava a cognição independente do social, para nos aproximarmos do paradigma interpretativista, que focaliza um pensamento construído na interação com o outro, num contexto social, de acordo com dialogismo bakhtiniano.

O cognitivismo iniciou um tipo de pesquisa em que os 'informantes' eram estimulados a elicitar seus processos mentais, porém de forma ainda monológica, pois o pesquisador não devia interagir com os informantes para não influenciar seus processos, o que era um resquício do objetivismo. No entanto, essa postura do pesquisador tornou a situação do pensar alto individual algo artificial, o que constrangia os informantes. É interessante observar aqui que o protocolo verbal continua sendo usado e que autores dos estudos de letramento, como Pressley e Hilden (2004), e da linguística aplicada, como McKay (2009), observam que é importante que a situação de ler pensando alto seja a mais natural possível. No entanto, foi possível ver pelas nossas pesquisas que a situação mais natural para pensar alto sem constrangimento foi sua realização em grupo (ZANOTTO, 1995).

A primeira geração de pesquisadores foi bem sucedida nos eventos do Pensar Alto em Grupo, porque tinham passado pela formação de pesquisadoras para utilizar o protocolo verbal. Eles sabiam que não podiam intervir para não influenciar os leitores e que a única possibilidade de intervenção era a de lembrar o informante de pensar alto, caso ele 
ficasse em silêncio. No entanto, quando passamos definitivamente para o Pensar Alto em Grupo, começaram surgir dificuldades, porque os professores/pesquisadores não tinham passado pela etapa do protocolo verbal e, por isso, traziam o papel de professor diretivo e controlador dos turnos, impedindo que o grupo interagisse na construção das leituras.

Esse fato me fez perceber que era necessário que eles revissem as próprias ações para coordenar o evento de leitura que era proposto. Percebi também que o PAG poderia facilmente ser desvirtuado. Muitos pesquisadores, ao tomar contato com ele, achavam que se tratava de um simples conversa, quando, na verdade, era uma conversa com características especiais, mas que precisavam ser delineadas mais claramente. Por essa razão, os professores interessados em utilizá-lo nas próprias pesquisas se dispuseram a realizar pesquisa-ação, e, para isso, trabalhavam (fora de sala de aula) com um grupo focal de cinco ou mais alunos, que participavam de quatro a seis eventos do Pensar Alto em Grupo, lendo diferentes textos. $\mathrm{O}(\mathrm{a})$ professor(a) pesquisador(a) analisava e refletia sobre as próprias ações nos eventos de leitura, para transformá-las.

Muitos professores se dispuseram a realizar a pesquisa-ação (NUNAN, 1992), contribuindo para delinear as ações e saberes necessários para coordenar o evento de leitura (ZANOTTO, 2014). Fomos construindo esses saberes na prática, analisando e refletindo colaborativamente sobre as vivências do PAG realizadas por eles. Essas análises nos levaram a tomar consciência da importância de dar espaço para a voz e subjetividade dos leitores e das implicações sociais e éticas desse traço essencial do Pensar Alto em Grupo. Se o leitor tinha espaço para sua voz e subjetividade, era importante que sua voz fosse ouvida e legitimada pelo professor/pesquisador e pelos outros leitores do grupo. Esse fato ressaltava a importância dos papéis do professor/ pesquisador como orquestrador das vozes dos leitores.

Assim, suas pesquisas contribuíram para delinear os saberes que precisam ser construídos: a) saber dar voz aos alunos; b) saber ouvir legitimando a voz do aluno e, muitas vezes, ampliando-a para o grupo (O'CONNOR; MICHAELS, 1996; VIEIRA, 1999); c) saber orquestrar as vozes dos participantes; d) saber mediar a co-construção das leituras; e) saber criar condições para que os alunos sejam mediadores entre si.

Desse modo, tomamos consciência de que a prática que estávamos construindo era coerente com a epistemologia do dialogismo, que possibilitou a sua fundamentação epistemológica.

\section{A epistemologia do dialogismo e o interpretativismo}

O texto de Marková (1997) veio ao encontro do que procurávamos: o dialogismo entendido como epistemologia, que possibilita a explicação da construção das leituras na interação em grupo. Essa autora propõe uma discussão sobre o monologismo e - dialogismo como epistemologias que se contrapõem, com base em Bakhtin (1979/1986)².

A epistemologia do monologismo é explicada pela autora como sendo a que concebe 'os objetos do conhecimento como entidades discretas' (MARKOVÁ, 1997, p. 227), as quais o conhecedor analisa objetivamente de um ponto de vista neutro. Essa é uma epistemologia objetivista, segundo Lakoff e Johnson (2002), por considerar separados o sujeito e o objeto, pois os objetos "têm propriedades independentes de quaisquer pessoas ou outros seres que os experienciem."(p. 295).

A epistemologia do dialogismo concebe 0 objeto do conhecimento como existindo apenas em relação a algo mais (MARKOVÁ, 1997, p. 228), ou seja, ele existe nainteração com o conhecedor,

\footnotetext{
${ }^{2}$ Marková se baseou na edição da Estética da Criação Verbal, traduzida do russo por C.Emerson\& M. Holquist, e ela afirma, no seu texto de 1997, que o termo Epistemologia vem dessa obra de Bakhtin. Em português, há duas edições em que o capítulo final, que nos chegou apenas esboçado, é traduzido de forma diferente: na ediçãode 2003, pela Editora Martins Fontes e traduzida da versão francesa, o capítulo recebeu o título deMetodologia das Ciências humanas. traduzido da versão francesa; e outro, publicado também pela Martins Fontes, em 1992,cuja tradução foi 'Observações sobre a epistemologia das ciências humanas. 'Marková, 1997 tem o mérito de sistematizar essa reflexão bakhtiniana sobre o dialogismo como epistemologia.
} 
constituindo os dois um 'todo relacional'. Por outro lado, "no processo de conhecer, o conhecedor toma uma perspectiva particular dos objetos de conhecimento ao invés de examiná-los 'objetivamente'”(p. 228). Em seguida, a autora dá exemplos de abordagens que partilham essa epistemologia: fenomenologia, interacionismo, construtivismo e o próprio dialogismo.

Além disso, eu acrescentaria que, embora Bakhtin não tenha elaborado uma 'teoria da leitura', as suas reflexões sobre a compreensão se aplicam ao processo da leitura e da construção do conhecimento. Ele concebe, por exemplo, a compreensão como sendo fundamentalmente reflexiva, pois pressupõe um envolvimento ativo do eu e do outro, que é fundamental na construção dos sentidos e dos sujeitos. Por essa razão, Marková observa que "qualquer ação comunicativa, por exemplo, um gesto ou um enunciado, é sempre uma ação construída conjuntamente pelos participantes envolvidos na comunicação" (p. 228). Um exemplo de construção conjunta ocorre quando um participante inicia o seu turno, mas é o outro que o completa e lhe atribui sentido. Isso traz uma implicação importante: a de que os interlocutores devem estar conscientes de si e do outro. Assim, a compreensão é responsiva e ativa, pois o outro não é passivo como na visão objetivista, mas é responsivo na construção de uma réplica ao seu interlocutor. É importante observar que a responsividade envolve o conhecedor inteiro, pois, como afirma Bakhtin (2003, p.348): "Nesse diálogo o homem participa inteiro e com toda a vida: com os olhos, os lábios, as mãos, a alma, o espírito, todo o corpo, os atos." Isso significa que a compreensão envolve a subjetividade do conhecedor.

Essa visão é afinada com a dointerpretativismo, que aceita a subjetividade na construção do conhecimento. Isso faz surgir a pergunta: seriam o interpretativismo e o dialogismo subjetivistas?Seriam sim, se não fosse considerada a intersubjetividade, "que possibilita chegarmos mais próximo da realidade que é constituída pelos atores sociais ao contrapormos os significados construídos pelos participantes do mundo social." (MOITA
LOPES, 1994, p. 332) Disso decorre uma nova noção de objetividade como fruto da intersubjetividade.

O interpretativismo, segundo Erickson (1986), teve a ideia seminal lançada por Dilthey, filósofo alemão do século XIX, que, ao propor a distinção entre as ciências naturais e as ciências humanas, "argumentou (...) que os métodos das ciências humanas deveriam ser hermenêuticos ou interpretativos (...) com o objetivo de descobrir e comunicar as perspectivas de interpretação do povo estudado." (ERICKSON, 1986, p. 123). No século XX, Bakhtin (1979/ 2003) propõe também o dialogismo como uma epistemologia para as ciências humanas.

Mas o gesto fundador do Interpretativismo foi de Malinowiski, no início do século XX, quando ele vai ao arquipélago Tobriand para observar in loco a cultura do povo que ali vivia, procurando interpretá-la com base nas vozes de seus membros, tomando a perspectiva do outro e, ao mesmo tempo, preservando sua subjetividade (ERICKSON, 1986). Essa foi uma autêntica atitudedialógica, mas inspirada em Dilthey e seus seguidores. Daí decorreu o traço essencial do interpretativismo, que consiste em ouvir as vozes dos participantes das práticas sociais investigadas, para poder compreender os significados construídos por eles no contexto em que estão inseridos.De certa forma, Malinowski também contribuiu para delinear outras características importantes dametodologiainterpretativista: a) preocupa-se em conhecer a interpretação do mundo social pelos participantes; b) baseia-se em métodos de geração de dados que são flexíveis e sensíveis ao contexto social em que os dados são produzidos, ou seja, é naturalística (porque estuda o fenômeno no seu contexto natural); c) adota uma visão holística dos fenômenos, pois considera todos os componentes do contexto, em suas interações e influências recíprocas; d) leva em conta os processos de intersubjetividade entre os participantes e o pesquisador.

\section{Completando o desenho : estratégias de pesquisa}


No paradigma interpretativista, desenvolvemos as nossas pesquisas, tendo como método principal o Pensar Alto em Grupo, associado a diários e entrevistas para possibilitar a triangulação dos dados. Para responder às questões da pesquisa relacionadas aos processos e o produto (as múltiplas leituras), é fundamental que vários grupos de leitores leiam o mesmo texto, constituindo assim, como estratégia de pesquisa, um estudo de caso coletivo instrumental (STAKE, 1998). É considerado instrumental porque "um caso particular é examinado para propiciar insight sobre uma questão ou refinamento de teoria" (STAKE, 1998, p. 88).

Esse desenho é articulado com o desenho da pesquisa-ação, que é realizada pelos professores/ pesquisadores do projeto, pois eles participam de vivências do PAG para se familiarizar com a prática e poder utilizá-la com os alunos, participantes de suas pesquisas.. Desse modo as vivências, das quais eles participam, geram dados para formar o estudo caso coletivo.

\section{Considerações finais}

Sintetizando, o projeto de pesquisa trabalha com dois focos, que exigem dois diferentes desenhos de investigação, mas que são articulados entre si por um processo colaborativo: a) investigar as ações do professor como orquestrador da prática do Pensar Alto em Grupo como método de pesquisa e vivência pedagógica - pesquisa-ação do professor/pesquisador sobre a própria prática; b) investigar as múltiplas leituras que emergem do protagonismo dos leitores - estudo de caso coletivo.

Nós buscamos a construção do Pensar Alto em Grupo como uma prática dialógica e colaborativa, dando espaço para que o leitor seja responsivo e reflexivo, pois isso interessa tanto para a pesquisa como para o ensino. Nossas pesquisas nos têm mostrado que o dialogismo pode ser um caminho muito produtivo para a pesquisa e o ensino.
AFFLERBACH, Peter. Verbal Reports and Protocol Analysis. In KAMIL, Michael L. et all (Eds.) Handbook of Reading Research. Mahwah, NJ: Erlbaum, 2000, p.163-179.

BAKHTIN, Mikhail. Estética da criação verbal.Tradução: Paulo Bezerra. 4. Ed. São Paulo: Martins Fontes, 2003.

CAMERON, Lynne. Metaphors in the learning of Science: A discourse focus. British Educational Research Journal, vol. 28, n. 5, p.673-688, 2002.

\section{.Metaphor in Educational Discourse.London, New York: Continuum, 2003. CARSTON, Robyn. Thoughts and Utterances: The Pragmatics of Explicit Communication.Oxford: Blackwell, 2002. \\ CANOLLA, Clemira F. A Compreensão Inferencial de Neologismos Literários. Mestrado. Programa de Linguística Aplicada e Estudos da Linguagem. Pontifícia Universidade Católica de São Paulo, São Paulo, 1995.}

CARSTON, Robyn. Thoughts and Utterances: The Pragmatics of Explicit Communication. Oxford: Blackwell, 2002.

CAVALCANTI, Marilda. The Pragmatics of FL ReaderText Interaction: Key Lexical Items as Source of Ppotential Reading Problem.PhDThesis. University of Lancaster, 1983.

Investigating FL Reading Performance through Pause Protocols.In C. Faerch; G. Kasper (Eds.) Introspection in SecondLanguageResearch.Clevedon, England: MultilingualMatters, 1987, p. 230-250.

$$
\text { Interação Leitor-Texto - Aspectos de }
$$
Interpretação Pragmática.Campinas: Editora da UNICAMP, 1989.

CAVALCANTI, Marilda C.; ZANOTTO, Mara S. Introspection in AppliedLinguistics: Meta-Researchon Verbal Protocols. In L. Barbara; M. Scott (Eds.) Reflections onLanguage Learning. Clevedon: Multilingual Matters Ltd., 1984, pp. 148-156.

COHEN, Andrew. Research on Cognitive Processing in Reading in Brazil.D.E.L.T.A., São Paulo, v.3, no 2,p.215-235, agosto, 1987.

CRESWELL, John W. Projeto de pesquisa - Métodos qualitativo, quantitativo e misto.Trad. Magda França Lopes. 3를 ed. Porto Alegre: Artmed, 2010.

DENZIN, Norman.K; LINCOLN, Yvonna S. (Eds.) The Landscape of Qualitative Research. London: Sage, 1998.

DENZIN, Norman.K; LINCOLN,Yvonna S.O Planejamento da Pesquisa Qualitativa - Teorias e

\section{Referências}


Abordagens. Trad.de Sandra R. Netz.Porto Alegre: Artmed, Bookman, 2006.

ERICSSON, K. Anders.; SIMON, Herbert A. Protocol Analysis. Cambridge, Mass: MIT Press / Bradford, 1984.

ERICSSON, K. ANDERS; SIMON, Herbert A. Verbal Reports on Thinking.In FAERCH, Claus; KASPER, Gabriele.Introspection in Second Language Research.Philadelpia, Multilingual Matters LTD, 1987, p. 24-53.

ERICKSON, Frederick. Qualitative Methods in Research on Teaching. In WITTROCK, Merlin C. (Ed.) Handbook of Research on Teaching. New York: MacMillan, 1986, p. 119-161.

FAERCH, Claus; KASPER, Gabriele (Eds.) Introspection in Second Language Research.Clevedon, UK: Multilingual Matters, 1987.

GIBBS, Raymond W. Researching Metaphor. In: CAMERON, Lynne; LOW, Graham (Eds.) Researching and Applying Metaphor. Cambridge: Cambridge University Press, 1999, p. 29-47.

GOOSSENS, Louis. Metaphtonymy: The Interaction of Metaphor and Metonymy in Expressions for Linguistic Action. In: DIRVEN, René; PÖRINGS, Ralf (Eds.) Metaphor and Metonymy in Comparison and Contrast. Berlin, New York: Mouton de Gruyter, 2003, p. 349-377.

GUBA, Egon G.; LINCOLN, Yvonna.Competing Paradigms in Qualitative Research. In: DENZIN, Norman; LINCOLN, Yonna (Eds.). The Landscape of Qualitative Research. London: Sage, 1998, p.195220.

HOSENFELD, Carol. Learning about learning: Discovering our Studies Strategies. ForeignLanguage ANNALS, 9, 1976, P. 117-129.

LAKOFF, George; JOHNSON, Mark.Metáforas da Vida Cotidiana.Trad.GEIM e coordenação M.S. Zanotto. São Paulo, Campinas: EDUC, Mercado de Letras, 2002

MARKOVÁ Ivana. LanguageandEpistemologyofDialogism.In STAMENOV, Maxim (ed.) Language Structure, Discourse and the Access to Consciousness. Amsterdam: John Benjamins, 1997, p. 227-250.

MCKAY, Sandra Lee. Introspective Techniques.In HEIGHAM, Juanita e Croker, Robert A. (Eds.)Qualitative Research in Applied Linguistics - A Practical Introduction. Hampshire: Palgrave Macmillan, 2009, p. 220-241.

MOITA LOPES, Luiz Paulo. Pesquisa Interpretativista em Linguística Aplicada: A Linguagem como Condição e Solução. D.E.L.T.A., São Paulo, vol.10, nº 2, p. 329-338, agosto , 1994.
Linguística Aplicada Indisciplinar. São

Paulo: Parábola, 2006.

Linguística Aplicada na Modernidade

Recente. São Paulo, Parábola, 2013.

NARDI, M. Isabel A. A Metáfora e a Prática de Leitura como Evento Social: Instrumentos do Pensar a Biblioteconomia do Futuro. Tese de Doutorado. PUCSP - LAEL, 1999.

As Expressões Metafóricas na Compreensão de Texto em Língua Estrangeira. Mestrado. Programa de Linguística Aplicada e Estudos da Linguagem, Pontifícia Universidade Católica de São Paulo, São Paulo, 1993.

NUNAN, David. Research Methods in Language Learning. Cambridge: Cambridge University Press, 1992.

NEWELL, A.; SIMON, K. Anders. Human Problem Solving. Englewood Cliffs, N.J.:Prentice-Hall, 1972.

O'CONNOR, Mary C. \& MICHAELS, Sarah.Shifting Participant Frameworks: Orchestrating Thinking Practices in Group Discussion.In HICKS. Deborah. (Ed.) Discourse, Learning and Schooling. Cambridge: Cambridge University Press, 1996, p 63-103.

OLCHAVSKY, J.E. Reading as ProblemSolving: AnlnvestigationofStrategies.

ResearchQuarterly, 12, 1976-1977: 654-674.

PALMA, Dieli V. A Leitura do Poético e as Figuras de Pensamento por Oposição: Caminhos e Descaminhos de Paradigmas na Modernidade. Tese de Doutorado, PUC-SP/LAEL, 1998.

PONTECORVO, Clotilde; AJELLO, Anna M; ZUCCHERNAGLIO, Cristina.Discutindo se aprende: interação social, conhecimento e escola.Trad.CláudiaBressan e Susana Termignoni. Porto Alegre: Artmed, 2005.

PRESSLEY, Michael; AFFLERBACH, Peter. Verbal Protocols of Reading: The nature of constructively responsive reading. Hillsdale, N.J.:Erlbaum, 1995.

PRESSLEY, Michael; HILDEN, Katherine.Verbal Protocols of Reading.In DUKE, Nell K.\& MALLETTE, Marlatt. (Eds.) Literacy Research Methodologies.N. York: The Guilford Press, 2004. P.308-321.

ROJO, Roxane. Letramentos Múltiplos, Escola e Inclusão Social. São Paulo: Parábola Editorial, 2009.

SIGNORINI, Inês; CAVANCANTI, Marilda C. Linguística Aplicada e Transdisciplinaridade. Campinas: Mercado de Letras, 1998.

SCHNEUWLY,Bernard.; DOLZ, Joaquim.Gêneros orais e escritos na escola.Trad. Roxane Rojo e Glaís Sales Cordeiro. Campinas: Mercado de Letras, 2004. 
STAKE, Robert E. Case Studies. In: DENZIN, Norman K.; LINCOLN, Yvonna S. Strategies of Qualitative Inquiry. London: Sage, 1998, p. 86-109.

STEEN, Gerard. Metaphor in Literary Reception.Doctoraldissertation.VrijeUniversiteit, Amsterdam, 1992.

Understanding Metaphor in Literature:

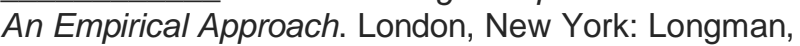
1994.

Processing Visual Metaphor: A Study in Thinking Out Loud.Metaphor and the Social World, Amsterdam, v.3.n.1.p.1-34,2013.

STREET, Brian.What's "new" in New Literacy Studies? Critical approaches to literacy in theory and practice. Current issues in comparative education.Columbia, v.5, n.2, p.77-91, 2003.

TENDAHL, Mark.A HybridTheoryofMetaphor. London, New York: Palgrave, Macmillan.

VIEIRA, Josalba R. Metáforas e Conflitos: A Leitura de Poesia e a Discussão em Grupo na Sala de Aula de Inglês como Literatura Estrangeira. Doutorado. Programa de Linguística Aplicada, Universidade Estadual de Campinas, Campinas, 1999.

ZANOTTO, Mara Sophia.Em busca da Elucidação do Processo de Compreensão da Metáfora. Trabalhos em Linguística Aplicada, Campinas, vol. 12, p.175189, jul./dez., 1988.

O Processo de Compreensão da Metáfora na Formação dos Professores de Língua Materna In: ZANOTTO (de PASCHOAL), Mara. Sophia;CELANI, Maria. Antonieta. Alba. (Orgs.), Lingüística Aplicada: da Aplicação da Lingüística à LingüísticaTransdisciplinar. São Paulo, EDUC.1992, p. 233-246.

ZANOTTO, Mara. Sophia. Metáfora, Cognição e Ensino de Leitura. D.E.L.T.A., São Paulo,vol 11, no 2, p. 241-254, agosto, 1995.

Construção e a Indeterminação do Significado Metafórico no Evento Social de Leitura. In: PAIVA, Vera L.M.O. Metáforas do Cotidiano. Belo Horizonte: Edit. da UFMG, 1998, P. 13-38.

ZANOTTO, Mara Sophia; PALMA.Dieli.V.Opening Pandora's Box: Multiple Readings of a Metaphor. In: ZANOTTO, Mara Sophia; CAMERON, Lynne; CAVALCANTI, Marilda. Confronting Metaphor in Use: An Applied Linguistic Approach.Amsterdam:JohnBenjamins.,2008, p. 11-43.

ZANOTTO, Mara Sophia.Multiple Readings of 'Metaphor' in the Classroom: Co-construction of Inferential Chains. DELTA, São Paulo, v. 26 especial, p.615-644, 2010.

ZANOTTO, Mara Sophia. A Construção de uma Prática de Letramento para o Ensino e Pesquisa de
Leitura da 'Metáfora' em Textos Literários. In Lima, Aldo de (Org.) A Propósito da Metáfora. Recife, Editora da UFPE, 2014, p. 193-241. 